\title{
NACIMIENTO DE LA PERSONA: PASADO Y PRESENTE
}

\author{
María-Eva Fernández BAQuero \\ Profesora Titular de Derecho Romano \\ Universidad de Granada \\ mefernan@ugr.es
}

\begin{abstract}
RESUMEN
La nueva regulación del art. 30 del Código Civil, en la que desaparecen los requisitos de tener figura bumana y vivir veinticuatro horas desprendido del claustro materno para la adquisición de la personalidad civil, nos impulsa a realizar una reflexión sobre la evolución que se ha producido en la concepción jurídica sobre el nacimiento de la persona física. Para ello hemos de tener presente tanto la tradición jurídica del Derecho romano, que siempre ba mostrado su influencia en este ámbito, como los criterios a seguir a tenor de la legislación sobre la investigación biomédica que en los últimos años se ha producido y que, indudablemente, nos ayuda a comprender la precisión técnica que debemos adoptar a la bora de definir al ser bumano en el momento de su nacimiento.
\end{abstract}

Palabras clave: Persona, personalidad jurídica, capacidad jurídica, nacimiento, vida, forma humana, viabilidad, feto, embrión, preembrión.

\section{ABSTRACT}

The new wording of article 30 of the Civil Code, where the requirements of having buman figure and living twenty-four hours outside the mother's womb, in order to acquire civil personality where we no longer find the requirements of having buman figure and living twenty four hours outside the maternal cavity, impels us to reflect upon the evolution that occurred in the field of the natural person's legal birth. In order to do so we should not only consider the tradition of Roman Law, which has always proved its influence in the field, but also the following criteria according to the regulation on biomedical investigation taken place in the past few years and which bas unquestionably belped us understand the technical precision which we should adopt when defining the buman being at the time of birth.

Keywords: Person, legal person, legal competence, birth, life, human shape, viabilility, fetus, embryo, pre-embryo.

\section{ZUSAMMENFASSUNG}

Die Neuregelung des Art. 30 des Spanischen Bürgerlichen Gesetzbuchs, in welchem die Voraussetzungen aufgeboben werden, nach welchen ein Neugeborenes menschliche Formen baben und 24 Stunden ausserbalb des Mutterleibs gelebt 
baben muss, um den Status der Juristischen Person erlangen zu können, regen uns zu Reflexionen über die stattgefundene Entwicklung des Rechtsbegriffs zur Geburt der natürlichen Person an. Hierzu müssen wir sowobl die Tradition des Römischen Rechts, das hierbei stets seinen Einfluss behauptete, berücksichtigen, als auch die Kriterien, welche die Rechtsgrundlage der biomedizinischen Forschung bilden, die sich in den letzten Jahren vollzogen hat. Letztere helfen uns, die technische Präzision zu verstehen, die wir anwenden müssen, wenn wir das menschliche Wesen bei seiner Geburt definieren wollen.

Schlüsselwörter: Person, JuristischePerson, Rechtsfähigkeit, Geburt, Leben, menschliche Form, Durchführbarkeit, Fötus, Embrio, embryonale Stammzellen.

SUMARIO: I. INTRODUCCIÓN.-II. PERSPECTIVA HISTÓRICO-JURÍDICA SOBRE LA PERSONALIDAD JURÍDICA.-III. REQUISITOS PARA LA ADQUISICIÓN DE LA CONDICIÓN DE PERSONA FÍSICA EN EL DERECHO ROMANO.-IV. SUPERVIVENCIA DEL DERECHO ROMANO EN LA TRADICIÓN JURÍDICA ESPAÑOLA.-V. LA NUEVA REDACCIÓN DEL ART. 30 DEL CÓDIGO CIVIL.-VI. CONCLUSIONES.

\section{INTRODUCCIÓN}

Con motivo del Congreso de Derecho y Biotecnología celebrado en la Facultad de Derecho de la Universidad de Granada los días 13 al 15 de diciembre de $2012^{1}$, dentro del apartado «Derechos de la persona y biotecnología», tuve la oportunidad de presentar una comunicación en torno a la nueva regulación del art. 30 del Código Civil, al ser definitivamente redactado por la disposición final tercera de la Ley 20/2011, de 21 de julio, del Registro Civil, estableciendo que «la personalidad se adquiere en el momento del nacimiento con vida, una vez producido el entero desprendimiento del seno materno». Dicha reforma entró en vigor al día siguiente de la publicación en el $B O E$, núm. 175, de 22 de julio, según la disposición final décima de dicha Ley. Con anterioridad a la reforma, el art. 30 disponía que: «Para los efectos civiles, sólo se reputará nacido el feto que tuviere figura humana y viviere veinticuatro horas enteramente desprendido del seno materno». En consecuencia, con la reforma mencionada se elimina en la redacción de dicho artículo dos requisitos necesarios para la adquisición

${ }^{1}$ Organizado por el proyecto de excelencia Avances e Invenciones Biotecnológicos. Aspectos Jurídicos (P07-SEJ-02887), con la colaboración del Departamento de Derecho Mercantil y Derecho Romano (Ámbito de Derecho Mercantil) de la Facultad de Derecho de la Universidad de Granada. 
de la personalidad civil: que el feto tenga figura humana y que deba vivir durante veinticuatro horas desprendido del seno materno.

En líneas generales, las opiniones más recientes de juristas españoles ${ }^{2}$ van en la dirección de acoger con buen grado las reformas señaladas por dos razones fundamentales: por un lado, consideran que los requisitos suprimidos del art. 30 (figura humana y vivir veinticuatro horas fuera del seno materno) responden a concepciones jurídico-sociales históricas (del Derecho romano y germánico) que no se corresponden con las consideraciones actuales, y por otro, la necesidad de adecuar nuestra legislación a los tratados internacionales ratificados por el Estado español, como son:

- El Pacto Internacional de Derechos Civiles y Políticos de 19 de diciembre de 1966 (BOE, núm. 103, de 30 de abril de 1977), en vigor en España desde el 27 de julio de 1977, cuyo art. 24.2 dispone: «Todo niño será inscrito inmediatamente después de su nacimiento y deberá tener un nombre».

- La Convención sobre los Derechos del Niño de las Naciones Unidas de 20 de noviembre de 1989 (BOE, núm. 313, de 31 de diciembre de 1990), en vigor en España desde el 5 de enero de 1991, cuyo art. 7.1 establece: «El niño será inscrito inmediatamente después de su nacimiento y tendrá derecho desde que nace a un nombre, a adquirir una nacionalidad y, en la medida de lo posible, a conocer a sus padres y a ser cuidado por ellos».

Si bien es necesario adaptar nuestra legislación a la normativa expresada en los tratados internacionales mencionados, sin embargo, no compartimos la primera de las razones apuntadas, esto es, que algunos de los requisitos para el reconocimiento de la personalidad civil, como es el de la exigencia de la figura humana contemplado en la redacción del anterior art. 30 del Código Civil, pueda considerarse en la actualidad desfasa-

${ }^{2}$ Véanse, entre otros, María Isabel de la IgLESIA Monje, «La reforma del art. 30 del Código Civil. Estudio de las condiciones del nacimiento. Repercusiones jurisprudenciales», Revista Crítica de Derecho Inmobiliario, núm. 728, noviembre de 2011, pp. 3403 y ss.; Carlos Martínez de AguirRe Aldaz, «La persona física: comienzo y fin de la personalidad», en Pedro de Pablo Contreras (coord.), Curso de Derecho civil. Derecho privado. Derecho de la persona, Madrid, 2011, pp. 331 y ss.; María Asunción LinACERO DE LA FuENTE, «La nueva redacción del art. 30 del Código Civil y la creación de un archivo especial para hacer constar los fallecimientos con posterioridad a los seis meses de gestación en la Ley 20/2011, de 21 de julio, del Registro Civil», Revista Crítica de Derecho Inmobiliario, núm. 731, mayo de 2012, pp. 1329 y ss., y Carles E. FlorENSA I Tomàs, «La modificación del criterio de adquisición de la personalidad civil: un análisis desde el Derecho civil catalán», InDret. Revista para el análisis del Derecho, octubre de 2012, pp. 1 y ss. 
do en el tiempo o anacrónico, como califican algunos autores que hemos mencionado ${ }^{3}$. El motivo principal de nuestro rechazo es porque a la hora de interpretar el actual art. 30 no se ha tenido presente suficientemente la Legislación sobre Investigación Biomédica (LIB) ${ }^{4}$, especialmente la Ley 14/2007, de 3 de julio (BOE, núm. 159), que nos aclara algunos conceptos o definiciones científicas y que puede arrojar nuevas conclusiones sobre el verdadero alcance y contenido del citado artículo.

En consecuencia, este trabajo pretende subrayar la necesidad de tener muy presente las opiniones de los científicos en investigación biomédica para poder interpretar en su justo alcance lo contenido en preceptos jurídicos que traten a la persona, ya que esa unión entre ciencia médica y ciencia jurídica es imprescindible en la actualidad ${ }^{5}$, como lo fue en el pasado, ya que así lo pusieron de manifiesto los juristas romanos en algunas de sus interpretaciones sobre los distintos requisitos que había que tener presentes en el momento del nacimiento del ser humano y su reconocimiento como persona. Por todo ello trataremos, en primer lugar, la evolución histórico-jurídica sobre la concepción de la personalidad jurídica, para pasar, en segundo lugar, a la exposición de los requisitos que se exigieron en el Derecho romano para la adquisición de la condición de persona física, continuaremos con la supervivencia del Derecho romano en la tradición jurídica española, para terminar con una reflexión de la nueva redacción del art. 30 del Código Civil y las conclusiones correspondientes a la luz de lo expuesto.

3 Véase nota 2.

${ }^{4}$ La legislación española recoge varias leyes con las que se ha ido regulando la reproducción humana asistida y la investigación biomédica. En concreto, cronológicamente, podemos señalar las siguientes: la Ley 35/1988, sobre técnicas de reproducción asistida; la Ley 42/1988, sobre donación y utilización de embriones y fetos humanos o de sus células, tejidos y órganos; la Ley 45/2003, que modifica los arts. 4 y 11 de la Ley 35/1988; la Ley 14/2006, sobre reproducción humana asistida; la Ley 14/2007, sobre investigación biomédica, que deroga la Ley 42/1988 antes mencionada, y, por último, el Real Decreto $1716 / 2011$, de 18 de noviembre, por el que se establecen los requisitos básicos de autorización y funcionamiento de los biobancos con fines de investigación biomédica y del tratamiento de las muestras biológicas de origen humano, y se regula el funcionamiento y organización del Registro Nacional de Biobancos para la investigación biomédica.

${ }^{5} \mathrm{La}$ industria biotecnológica ha situado la relación entre ciencia, ética y derecho en el núcleo del debate social. De ahí la creciente conexión entre bioética y derecho que, incluso, ha provocado la aparición de una nueva rama jurídica, conocida como bioderecho. Así, Ollero la define diciendo: «Una nueva rama jurídica caracterizada por su atención al respeto y protección de la vida humana, desde la concepción hasta su final» (Andrés Ollero, Bioderecho. Entre la vida y la muerte, Pamplona, 2006, p. 19). 


\section{PERSPECTIVA HISTÓRICO-JURÍDICA SOBRE LA PERSONALIDAD JURÍDICA}

Según nuestro Código Civil, el nacimiento y la muerte de la persona (arts. 29 y 32) delimitan el inicio y extinción de la personalidad civil o jurídica. Por tanto, «persona» y «personalidad» son conceptos que, aunque diferentes, están estrechamente unidos en la medida que, en el ámbito jurídico, ambos se apoyan mutuamente para configurar su significado. Esta interdependencia viene motivada por el hecho de que el término «persona» contiene un significado que va más allá de su sentido vulgar ${ }^{6}$, esto es, no es sólo el ser humano, sino todo ser capaz de ser sujeto de derecho, y, en consecuencia, nos enlaza con el concepto de personalidad que, en palabras de De Castro, sería: «La cualidad jurídica de ser titular y perteneciente a la comunidad jurídica, que corresponde al hombre (como tal) y que se reconoce o concede (traslativamente) a ciertas organizaciones humanas» ${ }^{7}$.

Ahora bien, en la Antigüedad, concretamente en el Derecho romano, la personalidad o capacidad jurídica del hombre, así como la de las organizaciones humanas, sólo fue reconocida en época avanzada. En los tiempos más antiguos, la cualidad de hombre no era suficiente por sí sola para alcanzar la capacidad de ser persona y tener personalidad jurídica. Suje-

${ }^{6} \mathrm{La}$ voz latina «persona» proviene de persono (de per y sono, as, are) que significaba «sonar mucho», «resonar». De ahí que el término personare, basado en Aulo Gelio, Noct. Att., V, 7, hace referencia a la máscara o careta que usaban los actores para representar a sus personajes y que, debido a la concavidad de la misma, servía al mismo tiempo para ahuecar o lanzar la voz: «"Personae" vocabulum quam lepide interpretatus sit quamque esse vocis eius originem dixerit Gavius Bassus. 1 Lepide mi hercules et scite Gavius Bassus in libris, quos de origine vocabulorum composuit, unde appellata "persona" sit, interpretatur; a personando enim id vocabulum factum esse coniectat. 2 Nam "caput" inquit et os coperimento personae tectum undique unaque tantum vocis emittendae via pervium, quoniam non vaga neque diffusa est, set in unum tantummodo exitum collectam coactamque vocem ciet, magis claros canorosque sonitus facit. Quoniam igitur indumentum illud oris clarescere et resonare vocem facit, ob eam causam "persona" dicta est "o" littera propter vocabuli formam productiore». También suelen relacionar este término con otro de origen etrusco: «phersus», escrito en la tumba de los Augures, relacionado con el personaje enmascarado participante en la escena. Cfr. Alfred ERnout y Alfred MEILLET, Dictionnaire étymologique de la langue latine, Paris, 1959, p. 500; Fulvio MAROI, «Elementi religiosi del diritto romano arcaico», $A G$, núm. 109, 1933, pp. 83 y ss.; Giambattista ImPaLLOMENI, voz «persona», en NNDI, vol. XII, 1965, pp. 1015 y ss.; Bernardo ALBANESE, voz «persona», en Enciclopedia del Diritto, vol. XXXIII, 1983, pp. 169 y ss.; Juan Miguel AlbURQUERQUE, en AAVV, Personalidad y capacidad jurídica, t. I, Córdoba, 2005, pp. 89 y ss., y Luis Enrique Antúnez y Villegas, «Sobre la institución "persona”», en Pedro Resina Sola (ed.), Fundamenta Iuris. Terminología, principios e interpretatio, Almería, 2012, pp. 65 y ss.

7 Federico de Castro y Bravo, Derecho Civil de España, vol. II, Pamplona, 2008, p. 31. 
to de Derecho únicamente era el paterfamilias o - lo que es lo mismotodo individuo que reuniese los tres status: libertatis (ser libre y no esclavo), civitatis (ciudadano romano) y familiae (ser sui iuris, que sobre él no se ejerciera ningún tipo de potestas, ya que él era el titular de la misma sobre todos los miembros - masculinos y femeninos- de su grupo familiar, alieni iuris). De ahí que Paulo (Lib. II ad Sabinum, D., 4, 5, 11) nos diga: «Tria enim sunt, quae babemus: libertatem, civitatem, familiam». Un cambio en cada uno de los estatus provocaba la capitis deminutio, que, al contrario de lo que aparentemente pudiera significar, no implicaba siempre una pérdida o disminución en la capacidad, ya que, en ocasiones, implicaba un incremento de la misma (por ejemplo, un alieni iuris que se convirtiera en paterfamilias y, por tanto, en persona sui iuris; ello suponía una conversión hacia una mayor capacidad aunque se considerase que había sufrido una capitis deminutio minima). En concreto, había tres grados de capitis deminutio: maxima, cuando el hombre pasa de ser libre a esclavo, y era máxima porque un cambio en ella afectaba directamente a la situación de los otros dos status (civitatis y familiae); media, implicaba un cambio en el status civitatis, afectando al status familiae, pero no al status libertatis, y, por útimo, minima, cuando el cambio afectaba exclusivamente al status familiae, pero no al status civitatis ni al libertatis. De ahí que en el mismo texto de Paulo antes mencionado en el Digesto se diga de forma expresa:

«Capitis deminutionis tria genera sunt: máxima, media, minima; tria enim sunt, quae babemus: libertatem, civitatem, familiam. Igitur quum omnia haec amittimus, hoc est, libertatem, et civitatem, et familiam, maximam esse capitis deminutionem; cum vero amittimus civitatem, libertatem retinemus, mediam esse capitis deminutionem; quum et libertas et civitas retinetur, familia tantum mutatur, minimam esse capitis deminutionem constat».

Por consiguiente, la única persona que adquiría plena capacidad jurídica o personalidad civil para ser sujeto del Derecho era el paterfamilias. Sin embargo, esta situación no quedó inalterada. Distintos factores irán provocando que poco a poco se dé la tendencia de hacer coincidir la capacidad jurídica o personalidad civil con la simple cualidad de hombre libre, ya que la esclavitud siempre estuvo presente en el mundo romano ${ }^{8}$. En concreto,

${ }^{8}$ Por ello, el jurista GAYO, Institutiones, I, 9, nos informa que la gran división referente al Derecho de las personas estriba en que de todos los hombres unos son libres y otros son esclavos: «Et quidem summa divisio de iure personarum baec est, quod omnes bomines aut liberi sunt aut sevi». 
los factores más destacados que, desde nuestro punto de vista, conducirían a conseguir la coincidencia antes mencionada serían los siguientes:

1. La influencia filosófica del estoicismo en la sociedad romana a partir de la República ${ }^{9}$, destacando el valor de la persona frente a la concepción del mundo antiguo. Concretamente, los estoicos se interesaban por los problemas relativos al comportamiento humano, defendiendo la igualdad de todos los hombres y propugnando un conjunto de preceptos morales cuyo objetivo principal era alcanzar la sabiduría y responder cuál debería ser la actitud del sabio frente a una situación determinada. Todo ello influiría en algunas reformas legales a través de las cuales se apreció una tendencia a mejorar progresivamente la situación de los esclavos, o bien a permitir una mayor emancipación de la mujer e, incluso, la relación paterno-filial fue adquiriendo un matiz más humanitario.

2. Iniciada la República, la civitas se fija en la familia para configurar una organización estatal semejante a la del pater con respecto a los filius. Potestas o auctoritas son términos que se trasladan a los distintos magistrados que, como el pater, gobernarán la respublica, iniciándose al mismo tiempo un control al mismo pater por medio de un magistrado: el censor, que controlará, mediante una nota censoria y la consiguiente merma en su capacidad de obrar como resultado de la ignominia e infamia, posibles comportamientos abusivos que tuviese con respecto a los miembros de su grupo familiar.

De esta forma, el poder público, a la vez que iba absorbiendo poderes y competencias que sólo el pater disfrutó con anterioridad, también comenzaba a admitir que la capacidad jurídica debía ir coincidiendo con el concepto de hombre libre. Prueba de ello fue la situación del filiusfamilias en esta misma época, que, una vez alcanzada la mayoría de edad y prestando sus servicios a la civitas como soldado, tenía la posibilidad de ocupar cargos públicos, alcanzando en muchos casos la condición de magistrado y, en definitiva, adquiriendo una potestas en la vida pública negada, sin embargo, en la privada e, incluso, enfrentándose a situaciones controvertidas en

9 Las fuentes históricas nos muestran que Atenas, en el año 155 a. C., envió a Roma una delegación con los representantes de las tres escuelas filosóficas más importantes: la estoica, la peripatética (de Aristóteles) y la académica (discípulos de Platón), encontrando buena acogida entre las grandes familias romanas. Poco después, años 180-110 a. C., Panecio de Rodas, distinguido maestro estoico, viajó a Roma entablando una gran amistad con Escipión Emiliano y encontrándose entre sus alumnos ilustres ciudadanos como el gran jurista y pontífice máximo Quinto Mucio Scévola. Véase, entre otros, José CastiLlejo, Historia del Derecho Romano. Política, doctrinas, legislación y administración, Madrid, 2004, pp. 154 y ss. 
cuanto a qué potestas tenía supremacía. En este sentido, los relatos de las fuentes literarias se muestran más inclinados a destacar que por encima de la patria potestas, propia del ius privatum, debería darse la potestas populi como materia del ius publicum. Así, Valerio Máximo (Factorum et dictorum memorabilium, II, 2, 4) nos muestra el suceso de Quinto Fabio Máximo, cónsul en el 213 a. C., y su padre procónsul y lugarteniente de su hijo, llamado también con el mismo nombre pero apodado «el Cunctator». Éste se encontró al hijo a caballo y, en contra de lo exigido por el poder público, el padre no bajó del caballo hasta que su hijo le ordenó a los lictores que le hicieran descender. Después de descender, orgulloso de su hijo, le dijo: «Hijo mío, no he hecho desprecio de tu suprema autoridad, sino que quise experimentar si sabes comportarte como un cónsul; por otra parte, no ignoro el respeto que se debe al propio padre, pero juzgo que las instituciones públicas son más importantes que el respeto privado» ${ }^{10}$.

3. El fenómeno de la expansión territorial del pueblo romano es otro factor importante, ya que, si bien posibilitará el enriquecimiento de su cultura con otras diferentes, sin embargo, tendrá que ir evolucionando hacia un proceso de apertura e integración de personas que, no disfrutando de la ciudadanía romana, fueran también reconocidas como sujetos de Derecho. Por ello, a partir del 241 a. C. surgió el pretor peregrino como magistrado competente para resolver los conflictos jurídicos entre ciudadanos romanos con extranjeros o bien entre extranjeros en territorio romano. De esta forma, junto al ius civile, el ius gentium, el ius naturale y el ius honorarium, irán desarrollando una nueva concepción en torno al Derecho de la persona, en el sentido de que persona debe coincidir con el de cualquier ser humano libre, dado que, como antes apuntamos, la esclavitud siempre estuvo presente en el pueblo romano. Así, Gayo [Institutionum, lib. I, D., 1, 5, 3 (= Inst., I, 8)] nos dice que la principal división en el derecho de

${ }^{10}$ El texto completo sería el siguiente: «Maxima autem diligentia maiores bunc morem retinuerunt, ne quis se inter consulem et proximum lictorem, quamuis officii causa una progrederetur, interponeret. filio dumtaxat et ei puero ante patrem consulem ambulandi ius erat. qui mos adeo pertinaciter retentus est, ut $Q$. Fabius Maximus quinquies consul, uir et iam pridem summae auctoritatis et tunc ultimae senectutis, a filio consule inuitatus ut inter se et lictorem procederet, ne bostium Samnitium turba, ad quorum conloquium descendebant, elideretur, facere id noluerit. Idem a senatu legatus ad filium consulem Suessam "Pometiam" missus, postquam animaduertit eum ad officium suum extra moenia oppidi processisse, indignatus quod ex XI lictoribus nemo se equo descendere iussisset, plenus irae sedere perseneranit. "quod cum filius sensisset, proximo lictori ut sibi appareret imperauit". cuius noci continuo Fabius obsecutus 'non ego' inquit, "fili, summum imperium tuum contempsi, sed experiri uolui an scires consulem agere: nec ignoro quid patriae uenerationi debeatur, uerum publica instituta prinata pietate potiora indico"». 
las personas es la de establecer que todos los hombres son libres o esclavos: «Summa itaque de iure personarum divisio haec est; quod omnes homines aut liberi sunt, aut servi». Aunque en otro momento, en Inst., I, 53, subraye la necesidad de dar un trato humano al esclavo y advierte de las consecuencias jurídicas negativas que a los dueños de los mismos les puede acarrear por un ejercicio abusivo y cruel sobre ellos ${ }^{11}$. La concepción de que todos los hombres nacían libres e iguales vendrá determinada por la influencia del ius gentium y del ius naturale, tal y como lo expresa Ulpiano en Lib. I, Institutionum, D., 1, 1, 4: «Ius gentium est, quo gentes humanae utuntur», y en Lib. XLIII ad Sabinum, D., 50, 17, 32: «Quod ad ius civile, servi pro nullis babentur; non tamen et iure naturali, quia, quod ad ius naturale attinet, omnes bomines aequales sunt».

4. Finalmente, la aparición del cristianismo sería decisivo para la confirmación definitiva de que la personalidad jurídica debe coincidir con la persona libre, imponiendo al jurista romano el respeto de la realidad espiritual del hombre, afirmando la condición de éste en valores transcendentales como podía ser: aequitas, bumanitas. De ahí que Justiniano considere a todos los hombres (ya sea varón o mujer, ya sea libre o esclavo) iguales en cuanto al culto de Dios, tal y como se aprecia en la Novela 5, 2:

«Eo quod omnes similiter divina suscipit gratia, praedicans palam quia, quantum ad dei cultum, non est masculus neque femina, neque liber neque servos: omnes enim in Christo unam mercedem percipere».

El cristianismo fue, en definitiva, la culminación de todo un proceso que se inició en periodos anteriores, desde la propia época republicana con el estoicismo, y que posibilitó la consolidación de los predicados de esta corriente religiosa ${ }^{12}$.

${ }^{11}$ «Sed hoc tempore neque civibus Romanis nec ullis aliis hominibus, qui sub imperio populi Romani sunt, licet supra modum et sine causa in servos suos saevire: Nam ex constitutione sacratissimi imperatoris Antonini, qui sine causa servum suum occiderit, non minus teneri iubetur, quam qui alienum servum occiderit. Sed et maior quoque asperitas dominorum per eiusdem principis constitutionem coercetur: Nam consultus a quibusdam praesidibus provinciarum de his servis, qui ad fana deorum vel ad statuas principum confugiunt, praecepit, ut si intolerabilis videatur dominorum saevitia, cogantur servos suos vendere. Et utrumque recte fit: Male enim nostro iure uti non debemus; qua ratione et prodigis interdicitur bonorum suorum administration».

12 Por ello, comparto la opinión de Veyne cuando señala que entre la época de Cicerón y el siglo de los Antoninos tuvo lugar en Roma una metamorfosis moral en el ámbito social y familiar de tal magnitud que el cristianismo encontró el terreno bastante abonado, por la influencia que fue ejerciendo tiempo atrás la filosofía estoica. La moral cristiana no hizo más 


\section{REQUISITOS PARA LA ADQUISICÓN DE LA CONDICIÓN DE PERSONA EN EL DERECHO ROMANO}

En el Derecho romano no existe una teoría uniforme sobre los requisitos exigidos para conseguir la condición de persona. De manera dispersa contamos con los criterios de los juristas que, a partir del periodo clásico, muestran su parecer sobre los mismos. De ellos se desprende que, desde el momento de la concepción, al nasciturus —aunque todavía no es persona- se le reconoce el derecho de adquirir todo aquello que le beneficie, nunca que le perjudique, con la única condición de que nazca con vida y con las exigencias que imponga el ordenamiento jurídico romano ${ }^{13}$. Por consiguiente, de las noticias contenidas en las fuentes podemos extraer los siguientes requisitos:

En primer lugar, el ser que nazca tiene que nacer de mujer libre, ya que nace esclavo el hijo de madre esclava aunque sea concebido por hombre libre. El criterio a seguir es siempre la condición jurídica de la madre y no la del padre, tal y como podemos ver en Gayo (Inst., I, 82): «Illud quoque his consequens est, quod ex ancilla et libero iure gentium seruus nascitur, et contra ex libera et seruo liber nascitur». Sin embargo, a partir del Derecho clásico, y con la intención de favorecer al nasciturus, se admitió la libertad del hijo si la madre fue libre en algún instante de la concepción. Así nos lo expresa Marciano (Lib. I. Inst., D., 1, 5, 5, 3):

«Ex hoc quaesitum est, si ancilla praegnas manumissa sit, deinde anciIla postea facta, aut expulsa civitate pepererit, liberum, an servum pariat? Et tamen rectius probatum est liberum nasci, et sufficere ei, qui in ventre est, liberam matrem vel medio tempore habuisse».

que retomar la moral existente en la etapa tardo-pagana. Cfr. Paul VEYNE, «La famille et l'amour sous le Haut-Empire romain», Annales ESC, núm. 33, 1968, pp. 36 y ss.

${ }^{13}$ Sobre el nasciturus cfr., entre otros, Emilio AlberTARIO, «Conceptus pro iam nato habetur (Linee di una ricerca storico-dommatica)», en Studi di dirito romano, vol. I, Milano, 1933 , pp. 3 y ss. (= en BIDR, núm. 33, 1923, pp. 1 y ss.); Gian G. ARCHI, voz «Concepimento (diritto romano)», en Enciclopedia del Diritto, vol. VIII, 1961, pp. 11 y ss.; Giuseppe GANDOLFI, voz «Nascita (diritto romano)», en Enciclopedia del Diritto, vol. XXVII, 1977, pp. 507 y ss.; María SALAZAR RevUeLTA, «Algunas consideraciones sobre la doctrina del nasciturus en la tradición romanística y en la codificación», en Problemática del Derecho romano ante la implantación de los nuevos planes de estudio, Jaén, 1999, pp. 289 y ss., y Juan Manuel BLANCH, «El concebido en el Derecho civil alemán, español e iberoamericano: un problema conceptual y valorativo a la luz de la tradición jurídica», en Anuario de Derecho Civil, 2001, pp. 1145 y ss. 
Este criterio sería posteriormente confirmado por Justiniano en Instituciones, 1 , 4pr., protegiendo al nasciturus diciendo expresamente que la desgracia de una madre no debe perjudicar al que está en el útero:

"Quia non debet calamitas matris ei nocere qui in utero est. ex his et illud quaesitum est, si ancilla praegnans manumissa sit, deinde ancilla postea facta peperit, liberum an servum pariat? et Marcellus probat, liberum nasci: sufficit enim ei qui in ventre est liberam matrem vel medio tempore habuisse: quod et verum est».

En segundo lugar, el nacimiento implicaba que el nuevo ser quedase separado por completo del claustro materno, totus processit ad orbem, sin lo cual mulieris portio est vicerum, según Ulpiano (Lib. XXIV ad ed., D., $25,4,1,1)^{14}$. Por otro lado, es indiferente que dicha separación se desarrollase mediante un parto natural o por cesárea, tal y como podemos apreciar en las opiniones de distintos juristas. En concreto, Ulpiano (Lib. IX ad Sabinum, D., 28, 2, 12pr.), cuando afirma que el hijo que nace después de hecho el testamento lo invalida, debe entenderse también en el caso de que se extraiga al hijo del vientre de la madre:

«Quod dicitur, filium natum rumpere testamentum, natum accipe, etsi exsecto ventre editus sit; nam et hic rumpit testamentum, scilicet si nascatur in potestate».

Opinión confirmada por el mismo jurista (Lib. VIII ad legem Iuliam et Papiam, D., 50, 16, 141) cuando establece que es hijo también cuando la mujer al morir pueda darlo a luz abriéndole el vientre:

«Etiam ea mulier cum moreretur creditur filium habere, quae exciso utero edere possit».

Por su parte, Marcelo nos recuerda una antigua lex regiae en la que se establecía la prohibición de enterrar a la mujer que estuviese embarazada sin proceder antes a extraer al feto del vientre de la misma; el que actuase de forma contraria sería considerado que mató una esperanza de vida (Lib. XXVIII Digestorum, D., 11, 8, 2):

${ }^{14}$ Juan Manuel Blanch, «El feto como porción de la mujer: origen de un mito jurídico», en El aborto, perspectiva pluridisciplinar, I Jornadas Universidad y Cultura de la Vida de la Fundación Universitaria San Pablo-CEU, Madrid, 2002, pp. 7 y ss., y Antonio FernÁndeZ DE BujÁn, Derecho privado romano, Madrid, 2012, p. 193. 
«Negat lex Regia, mulierem, quae praegnans mortua sit, bumari, antequam partus ei excidatur; qui contra fecerit, spem animantis cum gravida peremisse videtur».

En tercer lugar, tiene que producirse un nacimiento con vida, ya que los nacidos muertos se considera que no han nacido ni han sido procreados, porque nunca pudieron ser llamados hijos. Así nos dice Paulo (Lib. I ad legem Iuliam et Papiam, D., 50, 16, 129): «Qui mortui nascuntur, neque nati, neque procreati videntur, quia numquam liberi appellari potuerunts. En cuanto a la prueba de viabilidad ${ }^{15}$, esto es, que el recién nacido tenga posibilidades reales de vida independiente, hay que establecerla desde dos puntos de vista:

a) Atendiendo a los signos de vida del recién nacido, esto es, mientras que para los proculeyanos era necesario que emitiera gritos o llanto, para los sabinianos bastaba cualquier manifestación de movimiento; opinión esta última que asumió Justiniano en una constitución del año 530 (C., 6, 29, 3):

«Cumque sabiniani existimabant, si vivus natus est, etsi vocem non emisit, ruptum testamentum, apparet, quod, etsi mutus fuerat, hoc ipsum faciebat, eorum etiam nos laudamus sententiam et sancimus, si vivus perfecte natus est, licet ilico postquam in terram cecidit vel in manibus obstetricis decessit».

b) En función de la duración de la gestación, es decir, que se produzca pleni temporis, tras una gestación que haya durado seis meses completos (partus perfectus). Decisiones jurisprudenciales basadas en las opiniones de los científicos de la época, especialmente en Hipócrates. Así, Paulo (Lib. XIX Responsorum, D., 1, 5, 12) nos indica que, en base a la autoridad de Hipócrates ${ }^{16}$, el nacer al séptimo mes es un parto perfecto

${ }^{15}$ Véanse, entre otros, Rodolfo AmBrosino, «Il requisito della vitalità per l'acquisto della capacità giuridica in diritto romano», RISG, núm. 15, 1940, pp. 3 y ss.; Giambattista IMPALLOMENI, «Il tema di vitalità e forma umana come requisiti essenziali alla personalità», IURA, núm. 22, 1971, pp. 120 y ss.; Ana Alemán MonTERREAL, «La forma humana y su vinculación con la viabilidad: precedente romano del art. 30 del Código Civil», Actualidad Civil, núm. 35, 1999, pp. 1059 y ss., e íD., «Precisiones terminológicas sobre ostentum, D., 50, 16, 38 (Ulpianus libro 25 ad edictum)», en Pedro Resina Sola (ed.), Fundamenta Iuris. Terminología, principios e interpretatio, Almería, 2012, pp. 49 y ss.

${ }_{16}$ Entre los médicos griegos destaca especialmente Hipócrates (460-377 a. C.) al ser considerado el más importante de la antigüedad y el padre de la medicina. Se cree que nació en la isla griega de Cos y, aunque se sabe poco de su vida, las fuentes confirman que viajó mucho, aunque finalmente se quedó a vivir definitivamente en dicha isla donde enseñó medicina y trabajó como médico. Se le atribuyó el llamado Corpus hippocraticum, integrado por un conjunto de setenta obras sobre los conocimientos médicos de la escuela de Cos. 
y, por ello, si fue después de justas nupcias, el hijo nacido hay que considerarlo legítimo:

«Septimo mense nasci perfectum partum iam receptum est propter auctoritatem doctissimi viri Hippocratis: et ideo credendum est eum, qui ex iustis nuptiis septimo mense natus est, iustum filium esse».

En términos similares, Ulpiano (Lib. XIV ad Sabinum, D., 38, 16, 3, 12) confirma esta noticia cuando hace referencia al que nació a los 182 días calificándolo de iusto tempore:

«De eo autem, qui centensimo octogensimo secundo die natus est, Hippocrates scripsit et divus Pius pontificibus rescripsit, iusto tempore videri natum, nec videri in servitutem conceptum, cum mater ipsius ante centensimum octogensimum secundum diem esset manumissa».

Sin embargo, mayor problema presentaban los nacidos en el octavo y noveno mes de embarazo, ya que el nacimiento perfecto era el que se producía en el décimo mes al considerarse como el final de la gestación. Así, Aulo Gelio, Noctes Atticae, III, 16, 1-24:

«Et medici et philosophi inlustres de tempore bumani partus quaesi-

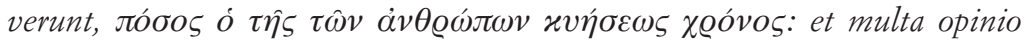
est, eaque iam pro vero recepta, postquam mulieris uterum semen, conceperit, gigni hominem septimo rarenter, numquam octavo, saepe nono, saepiusnumero decimo mense; eumque esse hominem gignendi summum finem, decem menses non inceptos, sed exactos».

Aunque puede sorprender que se hable de diez meses como tiempo normal de gestación, sin embargo, se puede explicar en el sentido de que

La importancia de este médico radica en su punto de vista antagónico a las creencias tradicionales que otorgaban a la enfermedad un carácter divino o castigo de los dioses. Frente a esta opinión, Hipócrates ofrece una visión racional en la que considera que las enfermedades son el resultado de los hábitos vitales, la alimentación y el ambiente. En consecuencia, este científico aparta la medicina de la superstición, la magia, la leyenda y las tradiciones basadas en espíritus malignos, duendes y otras criaturas que se apropiaban del organismo y le causaban enfermedades. Dentro del Corpus hippocraticum destacan los tratados ginecológicos, que tratan de las enfermedades y naturaleza de la mujer, así como la escisión del feto. Véase Juan Antonio López Férez, «Tratados hipocráticos. Estudios acerca de su contenido, forma e influencia», en Actas del VIIe Colloque International Hippocratique, Madrid, 24-29 de Septiembre de 1990, Madrid, 1992. 
una mujer, normalmente, da a luz pasados nueve meses, esto es, en el décimo mes, lo que no implicaría el tener que dar a luz a los diez meses ${ }^{17}$. De todas formas, no se puede establecer un tiempo exacto de gestación porque - como el mismo Hipócrates aclara - no todos los casos son iguales, según leemos en el texto citado:

«Hippocrates autem in eo libro, de quo supra scripsi, cum et numerum dierum, quibus conceptum in utero coagulum conformatur, et tempus ipsius partionis nono aut decimo mense definisset neque id tamen semper eadem esse fini dixisset, sed alias ocius fieri, alias serius, hisce ad postremum ver-

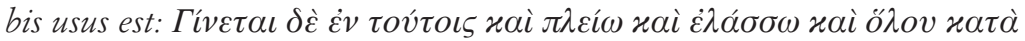

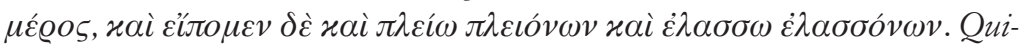
bus verbis significat, quod aliquando ocius fieret, non multo tamen fieri ocius, neque quod serius, multo serius».

Por otro lado, en el mismo fragmento Aulo Gelio recogía el problema que se presentaba cuando el parto se producía a los ocho meses, ya que Hipócrates, en su libro titulado Sobre los alimentos, señalaba que los mismos «existen o no existen», es decir —como bien explica el médico Sabino-, Hipócrates consideraba que «existen porque parecen estar vivos después del aborto, pero no existen porque luego de esto mueren. Así pues, existen y no existen, porque están vivos después del aborto, pero no existen porque están vivos un instante en apariencia, pero ya no en esencia»:

«Sed buius de mense octavo dissensionis causa cognosci potest in libro

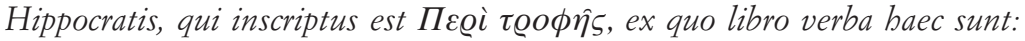

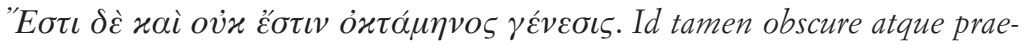
cise tamquam adverse dictum Sabinus medicus, qui Hippocratem commodis-

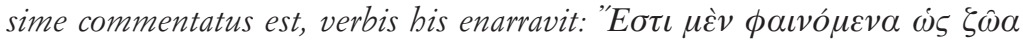

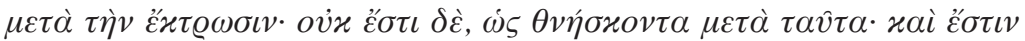

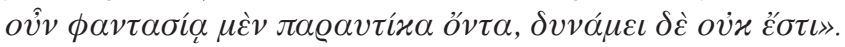

Así las cosas, un parto perfecto significa un parto no prematuro o viable. La no viabilidad, según Iglesias, puede ser entendida en dos sentidos: uno propio, es decir, cuando el nacimiento se produce antes de que el feto haya alcanzado en el claustro materno el desarrollo suficiente para seguir

${ }_{17}$ Véase, en este sentido, Antonio Ruiz dE Elvira, «Decem menses», CFC(L), núm. 10, 1996, pp. 115 y ss. 
viviendo después de salir a la luz, y otro impropio, no viable es la ineptitud orgánica para continuar la vida del parto maduro, de aquel que nació después de un periodo normal de gestación. De ahí que la doctrina no niege la personalidad jurídica al parto maduro, aunque un defecto orgánico le impida seguir viviendo. Por otro lado, el abortado puede nacer vivo. Pero el nacido vivo es aborto (abortus) cuando, por nacer prematuramente del claustro materno, no alcanza el desarrollo orgánico necesario para continuar con la vida. Sólo de tal causa depende la negación de la personalidad jurídica ${ }^{18}$.

Por último, en cuarto lugar se exige que el nacido tenga forma humana. Este requisito no ha estado, ni sigue estando, exento de polémica ${ }^{19}$. Dado que las decisiones jurisprudenciales se muestran en función de las necesidades prácticas, y siendo éstas muy variadas, las fuentes contenidas en la compilación justinianea nos dan soluciones diversas. En concreto, nos encontramos con dos posiciones diferentes mantenidas por los juristas Ulpiano y Paulo. El primero señala la posibilidad de contabilizar como hijos los nacidos sin la forma humana habitual, justificando que esta fatalidad no debe perjudicar a los padres. Así, Ulpiano (Lib. IV ad legem Iuliam et Papiam, D., 50, 16, 135) dice:

«Quaeret aliquis, si portentosum, vel monstrosum, vel debilem mulier ediderit, vel qualem visu, vel vagitu novum, non bumanae figurae, sed alterius, magis animalis quam bominis, partum, an, quia enixa est, prodesse ei debeat? Et magis est, ut haec quoque parentibus prosint: nec enim est quod eis imputetur, quae qualiter potuerunt, statutis obtemperaverunt, neque id, quod fataliter accessit, matri damnum iniungere debet».

En otro texto Ulpiano nos dice que invalida el testamento el que nació vivo pero no perfecto (Lib. IX ad Sabinum, D., 28, 2, 12, 1):

18 Juan IgLesIAS, Derecho romano. Instituciones de Derecho privado, Madrid, 1987, pp. 119 y 120.

${ }^{19}$ Véanse, entre otros, Rodolfo Ambrosino, «Il requisito della vitalità per l'acquisto della capacità giuridica in diritto romano», op. cit., pp. 1 y ss.; Biondo BIONDI, Istituzioni di diritto romano, Milano, 1965, pp. 113 y ss.; Giambattista ImPaLlomenI, «Il tema di vitalità e forma umana come requisiti essenziali alla personalità», op. cit., pp. 99 y ss.; Danilo DALla, «Status e rilevanza dell' "ostentum”», en Sodalitas. Scritti in onore de Antonio Guarino, vol. II, Napoli, 1984, pp. 519 y ss.; Juan IgLESIAS, Derecho romano. Instituciones de Derecho privado, op. cit., p. 190; Ana Alemán MONTERREAL, «La forma humana y su vinculación con la viabilidad: precedente romano del art. 30 del Código Civil», op. cit., pp. 1059 y ss., e ÍD., «Precisiones terminológicas sobre ostentum, D., 50, 16, 38 (Ulpianus libro 25 ad edictum)», op. cit., pp. 49 y ss. 
«Quid tamen, si non integrum animal editum sit, cum spiritu tamen, an adhuc testamentum rumpat? Et tamen rumpit».

Frente a estos textos, Paulo se manifiesta más tajante no otorgando la condición de hijos a los que nacen sin la forma humana habitual, como cuando una mujer da a luz algo monstruoso o anormal (Lib IV Sententiarum, D., 1, 5, 14):

«Non sunt liberi, qui contra formam bumani generis converso more procreantur: veluti si mulier monstrosum aliquid aut prodigiosum enixa sit. Partus autem, qui membrorum bumanorum officia ampliavit, aliquatenus videtur effectus et ideo inter liberos connumerabitur».

En el mismo sentido se puede leer en las Sentencias de Paulo, 4, 9, 3 :

«Mulier si monstruosum aliquid aut prodigiosum enixa sit, nibil proficit: non sunt enim liberi, qui contra formam bumani generis converso more procreantur».

La mayor parte de la doctrina considera que la diversidad de opiniones se debe a que Ulpiano hace una interpretación a tenor de lo establecido en la lex Iulia et Papia Poppaea, por la que Augusto otorgaba premios y beneficios a los que tenían hijos, imponiendo penas a los que carecían de ellos. De ahí que el hijo que naciera portentoso, monstruoso o sin la forma humana habitual no debía perjudicar a la madre ni a los padres, en general, si ello se debe a la fatalidad y éstos acataron lo ordenado, esto es, lo establecido en las leyes augusteas. Mientras que los textos de Paulo habría que analizarlos en función de lo establecido en el senadoconsulto Tertuliano que, bajo Adriano, otorgaba la herencia del hijo a la madre que gozase del ius liberorum, esto es, que hubiese procreado tres hijos (ius trium liberorum) si era ingenua, o bien cuatro (ius quattuor liberorum) si se trataba de una madre liberta.

Por nuestra parte, interpretamos que la exigencia de la forma humana viene establecida en el Derecho romano desde la época arcaica, cuando el ius y el fas estaban plenamente fusionados y el pueblo romano creía firmemente que un niño nacido monstruoso era un signo de ruptura de la pax deorum y la necesidad de su muerte podía ser interpretada como un acto expiatorio $^{20}$. En este sentido, Dionisio de Halicarnaso (Ant. rom., II, 15, 2)

20 Así, Tiтo Livio, Ab urbe condita libri, XXXIV, 45, 7; XXXV, 21, 3; XLI, 21,12, nos informa del nacimiento de niños con importantes deformaciones monstruosas que requerían 
nos informa que Rómulo estableció a sus habitantes la obligación de que criaran a todo vástago varón y a las hijas primogénitas y que no mataran a ningún niño menor de tres años, a no ser que fuese lisiado o monstruoso desde su nacimiento. Sin embargo, no impidió que sus padres lo expusieran tras mostrarlo antes a cinco vecinos más cercanos ${ }^{21}$. Estos comportamientos regulados por los mores maiorum o mores civitates supervivieron durante la Lex XII Tabularum, tab., IV, 1, tal y como lo recuerda Cicerón (Leg., III, 8, 19): «Cum esset cito necatus tamquam ex XII tabulis insignis ad deformitatem puer», ordenando la inmediata muerte del recién nacido que mostraba evidentes signos de deformación. Muerte que, normalmente, consistía en arrojarlo al mar ${ }^{22}$.

En la medida que el ius se va separando del fas, los mores maiorum se irán manteniendo siempre y cuando encuentren su fundamento no en la religión, sino en la razón y en la interpretatio que desarrollen los juristas romanos. En este sentido se comprende que Ulpiano y Paulo mostrasen sus pareceres basándose en las opiniones y experiencias de los científicos y médicos de la antigüedad, como son las referencias a Hipócrates que hacen ambos juristas en D., 38, 16, 3, 12, y en D., 1, 5, 12, respectivamente.

Ahora bien, las diferencias de opiniones entre ambos consideramos que se deben a distintos puntos de vista a la hora de definir qué debe entender-

de un acto expiatorio. Cfr., entre otros, Carla FAYER, La familia romana. Aspetti giuridici ed antiquari. Parte prima, Roma, 1994, p. 184, y Ana AlEmÁn MonterReAl «Precisiones terminológicas sobre ostentum, D., 50, 16, 38 (Ulpianus libro 25 ad edictum)», op. cit., p. 54.

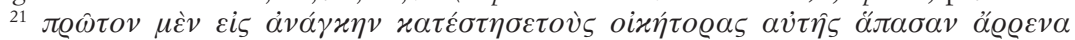

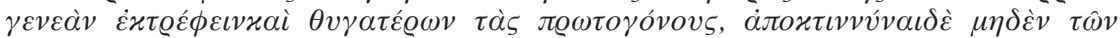

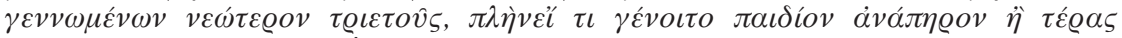

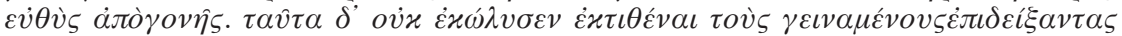

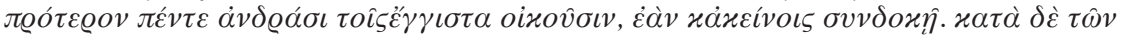

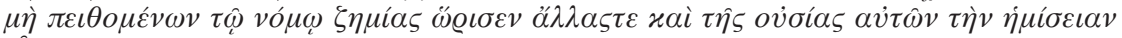

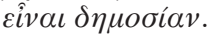

22 Seneca, Ira, I, 15, 2: "Quid enim est cur oderim eum cui tum maxime prosum cum illum sibi eripio? Num quis membra sua tunc odit cum abscidit? Non est illa ira, sed misera curatio. Rabidos effligimus canes et trucem atque inmansuetum bouem occidimus et morbidis pecoribus, ne gregem polluant, ferrum demittimus; portentosos fetus extinguimus, liberos quoque, si debiles monstrosique editi sunt, mergimus; nec ira sed ratio est a sanis inutilia secernere». Seneca, el Retórico, Controversiae, X, 4, 16: «TVRRINVS CLODIVS boc colore usus est: multos patres exponere solitos inutiles partus. nascuntur, inquit, quidam statim aliqua corporis parte mulcati, infirmi et in nullam spem idonei, quos parentes sui proiciunt magis quam exponunt. aliqui etiam vernulas aut omine infausto editos aut corpore invalidos abiciunt. ex his aliquos hic sustulit et eas partes, quae cuique possent miserabiliores esse, manu abstulit. stipem rogant et unius misericordia vivunt, omnium aluntur. 'at res foeda est mendicos habere, a mendicis ali, inter debiles versari.'age, non pudet vos ex hoc producere contubernio reum, (a) quo dicatis laesam rem publicam? et sic descendit ad argumenta, ut diceret: quomodo bic potuit laedere?». 
se por figura humana, así como las distintas consideraciones sobre enfermedades o defectos físicos que en algunos casos podían, o no, impedir la adquisición de la personalidad jurídica del recién nacido.

Como punto de partida, interpretamos que ambos juristas quieren precisar que la figura humana mínima que debe tener todo ser que nazca de una mujer después de un periodo de gestación pleno (el que nace al séptimo mes de embarazo según Paulo, D., 1, 5, 12, o bien después de 182 días de gestación según Ulpiano, D., 38, 16, 3, 12) debe ser la suficiente para permitirle desarrollar una vida propia, esto es, la que llevaría cualquier ser humano. Por ello, habrá defectos físicos que no impidan el que un ser que nace sea reconocido como persona y otros, en cambio, sí lo impidan.

De ahí que Ulpiano (Lib. XXV ad Ed., D., 50, 16, 38) nos diga que Labeo definió el «portento» como todo lo que se engendra o hace contra la naturaleza de una cosa. Distinguiendo dos clases de portentos: aquellos que nacen contra la naturaleza, por ejemplo, con tres manos o tres pies, de aquellos otros considerados prodigios y que los griegos llaman «fantasma» $(\phi \alpha v \tau \alpha ́ \sigma \mu \alpha \tau \alpha)$ :

"Ostentum" Labeo definit omne contra naturam cuiusque rei genitum factumque. Duo genera autem sunt ostentorum: unum, quotiens quid contra naturam nascitur, tribus manibus forte aut pedibus aut qua alia parte corporis, quae naturae contraria est: alterum, cum quid prodigiosum videtur, quae

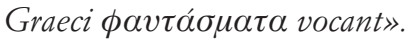

Por otro lado, Ulpiano, con motivo del estudio que hace del edicto de los ediles a tenor del ejercicio de la acción redhibitoria y quanti minoris en la venta de esclavos, realiza una detallada exposición distinguiendo entre lo que son enfermedades y vicios del cuerpo humano, y, dentro de estos vicios, los que son puramente físicos de los espirituales. Concretamente, en el Lib. I ad Ed. Aedilicium currulium, D., 21, 1, 1, 7, expone la definición de Sabino sobre lo que es enfermedad, estableciendo que es la conformación en un cuerpo contra lo natural, haciendo su uso menos apto para aquello que exija la naturaleza. Distinguiendo entre lo que es un vicio de lo que es una enfermedad, es decir, aclara que el vicio es un defecto pero no una enfermedad:

«Sed sciendum est morbum apud Sabinum sic definitum esse babitum cuiusque corporis contra naturam, qui usum eius ad id facit deteriorem, cuius causa natura nobis eius corporis sanitatem dedit: id autem alias in toto corpore, alias in parte accidere (namque totius corporis morbus est puta fvisis febris, partis veluti caecitas, licet homo itaque natus sit): vitiumque a morbo 
multum differre, ut puta si quis balbus sit, nam bunc vitiosum magis esse quam morbosum».

Además, Ulpiano se preocupa en diferenciar entre lo que son «vicios corporales» con respecto a los «vicios del espíritu», entendiendo que sólo los compradores podrían ejercitar la acción redhibitoria de aquellos defectos o vicios corporales que impidan el trabajo o servicio del esclavo, pero no ocurriría lo mismo con los vicios del espíritu que no tendrían que afectar a dicho uso o servicio del mismo. Así, en Lib. XLIV ad Sabinum, D., 21, 1, 9:

«Apud Vivianum quaeritur, si servus inter fanaticos non semper caput iactaret et aliqua profatus esset, an nibilo minus sanus videretur. Et ait Vivianus nibilo minus bunc sanum esse: neque enim nos, inquit, minus animi vitiis aliquos sanos esse intellegere debere: alioquin, inquit, futurum, ut in infinito bac ratione multos sanos esse negaremus ut puta levem superstitiosum iracundum contumacem et si qua similia sunt animi vitia: magis enim de corporis sanitate, quam de animi vitiis promitti».

Es verdad que Ulpiano en estos textos no menciona en ningún momento enfermedades o defectos físicos o mentales que afecten a la personalidad jurídica de la persona, pero sí está relatando las enfermedades y vicios que pueden encontrarse en los esclavos que, a pesar de ser considerados jurídicamente como cosas, su naturaleza humana los distingue del resto de los objetos del Derecho. Y, por ello, Ulpiano resalta que, dado el fin que se persigue con los esclavos, lo importante es la discapacidad física que impida un servicio idóneo de ellos, poniendo en un segundo plano los vicios considerados del espíritu (animi vitiis) en la medida que éstos afectarían a la inteligencia o mente del esclavo, no tan imprescindible como su fuerza física, ya que a éste principalmente se le exige que ejecute la voluntad de su dominus, no que desarrolle su propia voluntad. De ahí que los vicios en el espíritu no daban lugar al ejercicio de la acción redhibitoria por parte de los compradores de esclavos, tal y como el mismo Ulpiano nos informa en Lib. I ad Edictum Aedilium currulium, D., 21, 1, 1, 10: «Sed vitium animi, non corporis, ideoque redhibere non posse».

Curiosamente, al contrario de lo que pasa con los esclavos, en los hombres libres puede producirse la ruptura de un testamento, y, por tanto, ser heredero, para aquellos que tienen defectos físicos pero no en los considerados del espíritu; tal y como se aprecia en Lib. IX ad Sabinum, D., 28, 2, 12, 1: 
"Quid tamen, si non integrum animal editum sit, cum spiritu tamen, an adbuc testamentum rumpat? Et tamen rumpit».

Ahora, a diferencia del esclavo, se exige que el ser humano que vaya a ser considerado persona, aunque nazca con defectos físicos, deba reunir las condiciones mínimas para obtener la capacidad jurídica que se exige a cualquier persona; de ahí la expresión «cum spiritu tamen» que se contrapone con la expresión «animi vitiis» que aparecía en D., 21, 1, 9.

Por su parte, Paulo otorga mucha importancia a la apariencia humana como requisito de la personalidad jurídica del hijo que nace, tal y como vimos en D., 1, 5, 14 (=PS, 4, 9, 3), de tal manera que no son tenidos por hijos los que nacen sin la forma humana habitual, como cuando una mujer da a luz algo monstruoso o anormal. Sin embargo, en el mismo texto sigue diciendo que aquel que nace con miembros humanos en número superior al normal parece, en cierto modo, perfecto y, por tanto, se contará entre los hijos:

«Partus autem, qui membrorum bumanorum officia ampliavit, aliquatenus videtur effectus et ideo inter liberos connumerabitur».

Este texto nos invita a reflexionar sobre los miembros del cuerpo humano, es decir, sobre el número de órganos que debe tener un ser humano para ser considerado persona física, así como la importancia o supremacía de unos sobre otros. Por ello habría que preguntarse ¿qué es para Paulo un ser monstruoso o anormal? Expresamente no encontramos la respuesta en ningún texto, pero con motivo del texto anterior podemos apreciar que para el jurista clásico no tiene la consideración de monstruo el que nace con un número superior de miembros y, en consecuencia, sí podría ser considerado persona, probablemente porque considere que tales imperfecciones no tienen que afectar a su desenvolvimiento como persona física. Sin embargo, cuestión distinta es si el defecto se centra en la cabeza, ya que, para Paulo, este miembro es considerado como la parte principal del cuerpo humano. Así lo podemos ver en Lib. III Quaestionum, D., 11, 7, 44, cuando, con motivo de enterrar en diversos lugares las distintas partes de un cadáver, este jurista califica la cabeza como parte principal al considerarla como la imagen por la que somos conocidos:

«Cum in diverisis locis sepultum est, uterque quidem locus religiosus non fit, quia una sepultura plura sepulchra efficere non potest: mibi autem videtur 
illum religiosum esse, ubi quod est principale conditum est, id est caput, cuius imago fit, inde cognoscimur. Cum autem impetratur, ut reliquiae transferantur, desinit locus religiosus esse».

Por consiguiente, aunque también compartimos la opinión de aquellos que consideran que el requisito de la forma humana para el reconocimiento de la personalidad jurídica tuvo un distinto tratamiento jurídico en la lex Iulia y Papia Poppaea de época de Augusto con respecto a la recogida con relación al senadoconsulto Tertuliano, sin embargo, consideramos que no se dan importantes diferencias en la interpretación que en este ámbito realizan Ulpiano y Paulo. Concretamente, ambos dan menos importancia a los vicios o defectos físicos que a los vicios o defectos que afecten al espíritu (según Ulpiano) o a la cabeza (según Paulo) para la adquisición de la personalidad jurídica. De ahí que, desde nuestro punto de vista, podríamos interpretar una equiparación entre el texto de Ulpiano, D., $28,2,12$, 1, cuando considera que rompe testamento aquel que nace vivo, con espíritu, pero no perfecto, tal y como antes expusimos, con aquel otro texto de Paulo, D., 1, 5, 14, al estimar como hijo a aquel que nace con un número de miembros superior al normal. Se confirma esta identidad cuando Ulpiano, hablando de los esclavos, nos dice que no es importante el número de dedos que tenga en los pies o en las manos, siempre y cuando el esclavo pueda usarlos sin impedimento (Lib. I ad Edictum Aedilium curulium, D., 21, 1, 10, 2):

«Sed si quis plures digitos habeat sive in manibus sive in pedibus, si nibil impeditur numero eorum, non est in causa redhibitionis: propter quod non illud spectandum est, quis numerus sit digitorum, sed an sine impedimento vel pluribus vel pancioribus uti possit».

En los distintos supuestos, los juristas interpretan lo que son vicios o defectos físicos que no tienen razón de impedir al individuo un desenvolvimiento normal de persona física, siempre y cuando nazca después de 182 días de gestación, según Ulpiano (D., 38, 16, 3, 12), o en el séptimo mes de embarazo, según Paulo (D., 1, 5, 12).

En definitiva, la finalidad primordial del requisito de la forma humana era la de reforzar la viabilidad del ser que nacía y al poco tiempo moría por cualquier circunstancia, ya que los juristas romanos nunca tuvieron presente la necesidad de que transcurriese un tiempo determinado concreto para otorgarle personalidad jurídica desde que se producía el despren- 
dimiento del claustro materno del recién nacido. La figura humana era un signo objetivo de que se había producido el nacimiento de una persona física, siempre y cuando el nacido fuese libre y después del tiempo de gestación anteriormente mencionado.

\section{SUPERVIVENCIA DEL DERECHO ROMANO EN LA TRADICIÓN JURÍDICA ESPAÑOLA}

Tras la Compilación justinianea, el antiguo Derecho germánico exigió que el recién nacido viviera diez días para considerarlo persona, ya que, de esa forma, se reforzaba la aptitud para poder continuar una vida extrauterina; además, la ley Vestrogótica pedía que el niño fuese bautizado y la Alemánica que la criatura viviese una hora después de abrir los ojos. La justificación de imponer una hora era para que el recién nacido viese el cielo y las paredes de su casa ${ }^{23}$.

Entre los visigodos y los francos, para la adquisición de la capacidad jurídica se requería un reconocimiento oficial dentro del ámbito familiar similar al tollere liberos del Derecho romano ${ }^{24}$, ya que al recién nacido se le depositaba a los pies del padre para que éste procediera a cogerlo y alzarlo entre sus brazos. Más tarde, esto se producía con motivo de la imposición del nombre mediante el bautismo, que ocurría después de que el recién nacido hubiese sobrevivido nueve noches. Los pueblos longobardos y romanos que vivieron en el mismo reino tuvieron un tratamiento similar.

La influencia del Derecho romano y germánico se aprecia plenamente en el tratamiento jurídico de esta materia en el Derecho común, unién-

${ }^{23}$ Cfr. Blas Pérez GonzÁlez, «El requisito de la viabilidad del nacido en el Derecho civil», Revista Crítica de Derecho Inmobiliario, núm. 39, marzo de 1928, pp. 161 y ss., y Giuseppe GANDOLFI, voz «Nascita (diritto romano)», op. cit., pp. 515 y ss.

24 Tollere liberos o suscipere liberos era una ceremonia arraigada en las costumbres, principalmente de época republicana, de la que nos informan las fuentes literarias y diplomas militares, consistente en depositar a los recién nacidos a los pies del pater para que los reconociese como miembros legítimos del grupo familiar. Si el recién nacido era un varón, el pater tenía la opción de ejercitar el ius exponendi o bien de recogerlo del suelo, tomarlo entre sus brazos y alzarlo delante de todo el grupo familiar en reconocimiento de ser un nuevo miembro legítimo del mismo. Si se trataba de una mujer, también podría ejercitar el ius exponendi o bien ordenar que fuese alimentada. Cfr. Eva Cantarella, La calamidad ambigua, Madrid, 1991, p. 198; Carla FAYER, La familia romana. Aspetti giuridici ed antiquari. Parte prima, op. cit., pp. 181 y ss.; Armando Torrent RuIz, Diccionario de Derecho romano, Madrid, 2005, pp. 1361 y 1362, y María Eva FernándeZ BAQuero, «Definición jurídica de la familia en el Derecho romano», RDUNED, núm. 10, 2012, p. 158. 
dose a todo ello el Derecho canónico que, sin realizar modificaciones sustanciales, se aprecia su influencia en los juristas a la hora de interpretar las fuentes clásicas. Así, Baldo, comentando el texto de Paulo, D., 1, 5, 14, referente a la exigencia de la figura humana y que estudiamos con anterioridad, interpreta que el alma entra en el feto cuando éste comienza a asumir forma humana:

«Quod non habet corpus hominis, animam hominis non praesumitur babere, quia praesumitur, qunod natura no ponat animam, ubi non est corpus» 25 .

En la tradición jurídica española, el Fuero Juzgo estableció como prueba de viabilidad que el recién nacido viva diez días a partir del nacimiento y, como complemento esencial, que sea bautizado. Así aparece en la ley 18 del título $2{ }^{\circ}$ del libro IV:

«Establecermos que aquél que nasse non debe aver la buena de los padres, fueras si después que fue nascido recibiere baptismo e vizquere $X$ días».

Sin embargo, los diez días establecidos expresamente en la ley 18 son interpretados de manera más flexible por la ley 19 del mismo cuerpo legal al decir:

«El padre muerto si el fijo o la fija visquieren diez días o más o menos, o fuera baptizado cuanto que pertenecía de la buena del padre todo lo debe aver la madre».

Probablemente, el legislador quiso añadir en la ley 19 la posibilidad de contemplar soluciones más útiles y moldeables ante situaciones no previstas por la ley $18^{26}$.

Posteriormente, la ley $3 .^{a}$, título $6 .^{\circ}$, libro III, del Fuero Real trata también el origen de la personalidad, exigiendo sólo los requisitos de nacer con vida y ser bautizado, sin señalar plazo alguno de días ni de tiempo para acreditar la viabilidad:

25 Baldo Degli Ubaldi, In primam Digesti Veteris partem Commentaria, ad lib. I Digest., De statu hominum, lex XIIII, «Non sunt liberi», Venetiis, 1599, fol. 30, citado por Giuseppe GANDOLFI, voz «Nascita (diritto romano)», op. cit., p. 516.

${ }_{26}$ Véase Blas Pérez GonzÁLEZ, «El requisito de la viabilidad del nacido en el Derecho civil», op. cit., p. 171. 
«Si el que muriere dexare su mujer preñada, e no hoviere otros fijos, los parientes más propinquos del muerto en uno con la muguer escriban los bienes del muerto ante el alcante; e téngalos la muguer e si después naciere fijo o fija, e fuere baptizado baya todos los bienes del padre; e porque no se pueda facer engaño en la nascencia del fijo o de la fija del alcante con los parientes sobredichos pongan dos mugueres buenas, al menos que estén delante de la nascencia con lumbre; y no entre otra muguer a aquella hora fuera aqueIla que la bobiese a servir a la parición; y esta sea bien cargada, que no pueda facer engaño; e si la cruatura muriere antes de ser baptizada, hereden su buena los parientes más propinquos del padre, e no de la madre e si después que fuere baptizada muriere berebedelo la madre».

Como señaló Pacheco ${ }^{27}$, el Fuero Real se inspiró en el Fuero Juzgo y, dado que la ciencia médica del momento no produjo ningún cambio en la materia, podemos presumir que los plazos del Fuero Juzgo se mantendrían inalterados, dado que la exigencia del bautismo era una prueba de que el recién nacido — para ser persona- debía vivir algún tiempo fuera del seno materno, más aún cuando la ley 19 del Fuero Juzgo flexibilizaba la determinación del tiempo que la criatura se mantendría con vida cuando introdujo en el texto legal la expresión más o menos.

Ahora bien, donde podemos observar una mayor supervivencia del Derecho romano es en Las Siete Partidas de Alfonso X El Sabio, ya que de su lectura se desprende que son dos los requisitos exigidos al recién nacido para considerarlo persona: que nazca vivo y que tenga figura humana.

El primero de ellos viene recogido en la Partida VI, 6, 16, con motivo de la sucesión sin testamento de un hombre que deja embarazada a su mujer:

«Sin testamento muriendo algún ome, dexando su mujer preñada o cuidando que lo era, decimos que nin hermano nin otro pariente del muerto, non deue entrar la heredad del finado; ante deue esperar, fasta que la muguer encaezca. E entonces, si el fijo o la fija nasciere viuo, el aurea la beredad en los bienes del padre».

Como se puede apreciar, se sigue el requisito romano de que nazca con vida, aunque no aporta nada nuevo en cuanto a la solución que Justiniano dio referente a la disputa de proculeyanos y sabinianos en torno a la viabilidad. Siguiendo, además, la necesidad de que se produzca un

${ }^{27}$ Francisco PACHECO, Comentario histórico, crítico y jurídico a las leyes de Toro, t. I, pp. 203 y ss., citado por Blas Pérez GonZÁLEZ, «El requisito de la viabilidad del nacido en el Derecho civil», op. cit., p. 172. 
parto perfecto, esto es, que el feto contenga el tiempo necesario de gestación, admitiendo la posibilidad de que nazca entre los siete y diez meses de embarazo, tal y como se puede ver en la Partida IV, 23, 4:

«Lo más que la muguer preñada puede tener la criatura en el vientre son diez meses. Otrosi la criatura que nasciere fasta en los siete meses, que solo que tenga un día del septimo mes, que es cumplida e vivvidera. Eso mismo debe ser jujado de la que nasce fasta en los nueve meses».

El segundo de los requisitos mencionados, la figura humana, viene recogido en la Partida IV, 23, 5:

«Non deben ser contados por fijos los que nacen de la muguer et non son figurados como omes, asi como si hobiesen cabeza u otros miembros de bestia. Mas si la criatura que nasce ha figura de ome muguer haya miembros sobejanos o menguados, no empesce para poder heredar los bienes de su padre et de su madre et de otros parientes».

La supervivencia del Derecho romano es clara al no mencionar plazo de tiempo alguno para el reconocimiento de la persona. Tampoco se habla de la necesidad del bautismo y niega personalidad a aquellos que nacen con una deformación orgánica que les impide vivir, a diferencia de aquellos que, teniendo sólo un defecto físico no esencial para la vida, se consideren viables. Por otro lado, el rey Sabio distingue entre los órganos importantes la cabeza, tal y como hiciera Paulo en D., 11, 7, 44, ya que en ella podemos diferenciar al hombre del resto de los seres vivos de la naturaleza. Por consiguiente, en las Partidas es donde encontramos una mayor influencia de la legislación romana en el tema del reconocimiento de la personalidad jurídica, al exigir que nazca vivo, tras un periodo mínimo de gestación concretado en el séptimo mes, y que la criatura tenga forma humana.

La diversidad y variedad de criterios de las disposiciones anteriores, uniéndose a ellos los Fueros municipales que exigían el nacimiento con vida, aptitud para vivir y un tiempo medio - como prueba de la viabilidad - que oscilaba entre las veinticuatro horas y diez días, así como la condición del bautismo, dio lugar a que las Leyes de Toro tratasen de solventar la difícil situación. Con tal motivo se redactó la ley XIII, que de manera clara expone la situación y la consiguiente interpretación:

«Para evitar muchas dubdas que suelen ocurrir acerca de los fijos que mueren rezien nacidos, sobre si son naturalmente nacidos o son abortivos, 
ordenamos y mandamos quel tal fijo se diga que naturalmente es nacido, $e$ que no es abortivo quando nasció bivo todo, e que a lo menos después de nacido bivió veynte e quatro oras naturales, e fué baptizado antes que moriese, y si de otra manera nascido, murió dentro de dicho término o no fué baptizado, mandamos que tal fijo sea avido abortivo e que no pueda heredar a sus padres, ni a sus madres, ni a sus ascendientes; pero si por el absencia del marido, o por el tiempo del casamiento claramente se provase que nasció en tiempo que no podia bivir naturalmente, mandamos que aunque concurran en el dicho fijo las cualidades susodichas, que no sea avido por parto natural ni lejitimo».

Como se puede ver, el texto se compone de dos partes bien diferenciadas. En la primera trata de distinguir entre los que son «naturalmente nacidos» de los «abortivos». Para los primeros, deben reunir tres requisitos esenciales: $a$ ) nacer vivo todo; $b$ ) vivir veinticuatro horas naturales, y c) ser bautizado antes de morir. Faltando alguno de estos requisitos, el recién nacido que muere es considerado abortivo. En la segunda parte se contempla la legitimación o no de los hijos póstumos, considerando abortivos todos aquellos que nacen en un corto periodo de tiempo, insuficiente para poder vivir, desde que se ausentó el padre o desde la fecha del matrimonio, aunque el recién nacido muriese cumpliendo los requisitos mencionados en la primera parte del texto.

Son variadas las interpretaciones que se han vertido sobre este texto ${ }^{28}$, probablemente todas ellas complementarias, que conducen al intento de conciliar tanto el contenido de las fuentes romanas como el Derecho germánico y el Derecho canónico. En efecto, las fuentes romanas se reflejan en el primer requisito: «nacer vivo todo», es decir, que, cumplido el periodo mínimo de gestación y una vez separado del claustro materno, el recién nacido tenga la figura humana o los órganos necesarios para identificarlo como un ser humano apto para ser persona. Mientras que el requisito de las veinticuatro horas es propio del Derecho germánico, con el fin de dar una seguridad de viabilidad en el tiempo. Por último, el Derecho canónico marca su influencia, por un lado, en la exigencia del bautismo y, por otro, fomentando el matrimonio legítimo al imponer una dura medida a los recién nacidos que (a pesar de cumplir los requisitos antes mencionados) nazcan y posteriormente mueran en un plazo de tiempo demasiado corto (insuficiente para poder vivir) desde el momento en que se ausentó el padre, o desde que se produjo la fecha del matrimonio.

${ }^{28}$ Véase PÉREZ GONZÁLEZ, B., Blas PÉREZ GONZÁLEZ, «El requisito de la viabilidad del nacido en el Derecho civil», op. cit., pp. 324 y ss. 
La importancia de esta ley se aprecia por la influencia que ha ejercido en textos jurídicos posteriores hasta llegar prácticamente a nuestros días. Así, Felipe II la incorporó al texto de la Novísima Recopilación en la ley II, título V, libro X. Más tarde, el Proyecto de Código Civil de 1851, de García Goyena, en su art. 107 exigía la figura humana y cuarenta y ocho horas de supervivencia, diciendo: «Para los efectos legales, sólo se reputa nacido el feto que, desprendido enteramente del seno materno, nace con figura humana y vive cuarenta y ocho horas naturales». Finalmente, la Ley del Matrimonio Civil de 1870 consignó en su art. 60: «Para los efectos civiles, no se reputará nacido el hijo que no hubiere nacido con figura humana y que no viviera veinticuatro horas enteramente desprendido del seno materno». Por consiguiente, este texto fue el antecedente inmediato y modelo empleado por el legislador del Código Civil de 1889 para redactar el art. 30, actualmente derogado por la Ley 20/2011, que será objeto de nuestra reflexión —en el apartado siguiente- junto con la nueva redacción otorgada al mismo.

\section{LA NUEVA REDACCIÓN DEL ART. 30 DE CÓDIGO CIVIL}

Con la aparición de la Ley 20/2011, de 21 de julio, del Registro Civil, se produce una importante transformación en el contenido del art. 30 del Código Civil, ya que se da una nueva redacción a este precepto —en la disposición final tercera de dicha Ley- al establecerse que «la personalidad se adquiere en el momento del nacimiento con vida, una vez producido el entero desprendimiento del seno materno». Con anterioridad, dicho artículo disponía: «Para los efectos civiles, sólo se reputará nacido el feto que tuviese figura humana y viviere veinticuatro horas enteramente desprendido del seno materno». La mayoría de la doctrina civilista coincide en resaltar y elogiar la supresión de dos requisitos históricos: por un lado, la exigencia de la «figura humana» (con claros antecedentes en el Derecho romano) y, por otro, el plazo de supervivencia de las «veinticuatro horas» (originario de los Derechos germánicos), ya que consideran que ambos requisitos son en la actualidad desfasados y anacrónicos, tal y como indicamos en la introducción de este trabajo ${ }^{29}$.

Sin embargo, desde nuestro punto de vista, la nueva redacción del art. 30 del Código Civil, por una lado, aunque no lo manifieste de forma

\footnotetext{
${ }^{29}$ Véase nota 2.
} 
expresa, mantiene viva la tradición del Derecho romano a la hora de concretar los requisitos para la adquisición de la personalidad, pero, por otro, apreciamos un contenido impreciso y poco acorde con la legislación biomédica (Ley 17/2007, de 3 de julio, de investigación biomédica) en algunos de sus términos y expresiones, pudiendo dar lugar a ciertas incertidumbres.

Los dos únicos requisitos que se exigen para la adquisición de la personalidad en la actualidad son: el nacimiento con vida y que se produzca un entero desprendimiento del seno materno. Como se puede apreciar, ambos tienen su naturaleza jurídica en la legislación romana, según tuvimos ocasión de analizar. Sin embargo, lo que no aclara la nueva redacción del art. 30 son los signos de vida o viabilidad que hay que tener presentes para valorar adecuadamente si el ser que ha nacido tuvo - aunque fuese por un instante - vida y, en consecuencia, personalidad jurídica antes de su fallecimiento. En este sentido recordemos que en Derecho romano se consideraba que había vida cuando el nacido se movía y tenía figura humana, una vez separado del claustro materno y tras seis meses de gestación como mínimo. Con anterioridad al actual art. 30, la vida se comprobaba con la prueba de la viabilidad en sus dos vertientes: la figura humana y vivir separado del claustro materno veinticuatro horas. Distinguiendo, por tanto, la «viabilidad legal» frente a la «viabilidad natural o médico-biológica» ${ }^{30}$.

Desaparecidas ambas vertientes de viabilidad en la nueva redacción de dicho artículo, no nos queda más remedio que presumirla en base a los indicios que se desprenden del contenido de otras normas y de las opiniones de los científicos reflejadas en la legislación biomédica. El problema se presenta ante el fallecimiento del recién nacido en un instante muy cercano a su nacimiento, cuando todavía ni siquiera se había realizado la inscripción del mismo. En tales casos, la prueba de la viabilidad tiene que apoyarse en las certificaciones médicas de los especialistas que asistieron al parto y posterior fallecimiento. Ante un alumbramiento fuera de un centro sanitario y no interviniendo en el parto un especialista sanitario, el padre

${ }^{30}$ Este último criterio es el empleado actualmente por el Código Civil francés, distinguiendo los conceptos que interpretara De Castro al diferenciar entre: «viabilidad propia», entendida como la madurez fetal o estado del feto de, al menos, una mínima aptitud para vivir, dado el tiempo de su desarrolla intrauterino. Distinta a ella estaría la «viabilidad impropia» o carencia de vicios teratológicos, es decir, estado del feto que presente, al menos, mínima aptitud para vivir, por no tener defectos orgánicos, detención o perversión del desenvolvimiento, enfermedad o lesión intra o extrauterina de consecuencias mortales, según la definición dada por el mencionado autor. Véase Federico De CASTRo y BRAvo, Derecho Civil de España, op. cit., pp. 106 y ss. 
o la madre o el pariente más próximo harán la declaración de nacimiento y posterior defunción, pero en cualquier supuesto se necesita una certificación médica que habrá que presentar en el Registro Civil. Todo ello se regula en los arts. 44, 45, 46, 47 y 66 de la Ley 20/2011, de 21 de julio, del Registro Civil.

Por consiguiente, la prueba de la viabilidad queda sometida no a una apreciación basada en datos perfectamente visibles por cualquiera (figura humana y separación del claustro materno veinticuatro horas, como antes se exigía), sino a la apreciación de los especialistas sanitarios (médicos), ya que, tras el examen del recién nacido, son ellos los que determinarán qué «tipo o fase de vida» tenía para considerarlo, o no, un sujeto del Derecho, aunque posteriormente muriese. Por ello consideramos muy importante la Ley 14/2007, sobre investigación biomédica, en la que encontramos el art. 3, titulado «Definiciones», en donde se exponen veinticuatro conceptos que se apoyan en conocimientos científicos, técnicos y jurídicos. Entre dichas definiciones algunas son especialmente interesantes, ya que nos aclaran las distintas fases de la vida del ser humano antes de su nacimiento, y basándonos en ellas adelantamos nuestras conclusiones al considerar que, desde nuestro punto de vista, el requisito de la figura humana - no mencionado en el nuevo art. 30 del Código Civil- sigue estando vigente a pesar de que la doctrina lo considere eliminado.

En concreto, el razonamiento de nuestra interpretación parte de la Ley 14/2007 que define claramente la diferencia entre «embrión» y «feto» diciendo:

«Embrión: fase del desarrollo embrionario que abarca desde el momento en el que el ovocito fecundado se encuentra en el útero de una mujer hasta que se produce el inicio de la organogénesis y que finaliza a los cincuenta y seis días a partir del momento de la fecundación, exceptuándose del cómputo aquellos días en los que el desarrollo se hubiera podido detener» [art. 3.l)].

«Feto: embrión con apariencia humana y con sus órganos formados que va madurando desde los cincuenta y siete días a partir del momento de la fecundación, exceptuando del cómputo aquellos días en los que el desarrollo se hubiera podido detener, hasta el momento del parto» [art. 3.n)].

La regulación jurídica de las investigaciones biomédicas muestra de manera muy clara que la vida biológica del ser humano comienza desde la fecundación y evoluciona en distintas fases. En todas ellas hay vida. Lo que ocurre es que para la adquisición de la personalidad jurídica hay que alcan- 
zar una determinada fase de vida, lo suficientemente evolucionada (apariencia bumana y con sus órganos formados), para ser sujeto del Derecho tras el nacimiento o separación del seno materno. En este sentido, aunque el art. 30 del Código Civil omita la expresión «feto» y «figura humana», no significa que no se exija, puesto que, tras el nacimiento y separación del seno materno y posterior fallecimiento, el médico tendrá que certificar si nació con vida apta para poder subsistir como cualquier persona de no haberse producido el fallecimiento.

Consideramos, desde nuestro punto de vista, que es importante discernir entre la existencia de vida humana que se admite en el mundo de la ciencia y el criterio de vida que el mundo del Derecho delimita en cada momento histórico. Por ello, mientras que los científicos establecen una variedad muy amplia de tipos o fases de vida biológica que se inicia desde la fecundación, ya sea natural o in vitro ${ }^{31}$; sin embargo, los juristas parten del nacimiento o separación del seno materno para verificar si el ser nacido tuvo o no vida. Por esta razón, los especialistas sanitarios cuando tienen que certificar la existencia de una vida humana —en coherencia con las exigencias del ordenamiento jurídico- tienen que concretar o acotar más los requisitos para la misma, observando que el ser que nace separándose del seno materno tiene o ha tenido (aunque sea por un instante) una vida apta para poder continuar existiendo como persona.

En este sentido, uno de los criterios que se siguen en el mundo de la ciencia para determinar el inicio de la vida de un ser humano, desde el punto de vista de los requisitos requeridos por el Derecho, es el de la «independencia corporal», que, según los propios científicos, encuentra su primitiva regulación en el Derecho romano ${ }^{32}$. Así, autores como Luis Vivanco, Alfredo Mar-

${ }^{31}$ En efecto, la Ley 14/2007 (LIB), además de los conceptos de «embrión» y «feto», anteriormente expresados, también define al «preembrión» diciendo en el art. 3.s): «El embrión constituido in vitro formado por el grupo de células resultante de la división progresiva del ovocito desde que es fecundado hasta catorce días más tarde». Todas estas definiciones jurídicas del mundo científico han sido interpretadas por autores como Zurriaráin diciendo lo siguiente: «Paradójicamente, las Leyes 14/2006 y 14/2007 definen al "preembrión" no como un grupo de células (Ley 35/1988), sino como un embrión. El feto también es definido como un embrión. Estas definiciones manifiestan que el "preembrión”, el embrión y el feto se constituyen en la fecundación, pues sin ésta no hay ni "preembrión", ni embrión, ni feto. Luego la fecundación es el momento en que se inicia el ser humano que va desarrollándose paulatinamente» (Roberto Germán ZurRiaráin, Cuadernos de Bioética, vol. XX, 2. ${ }^{a}$ ed., 2009, p. 175, n. 39).

32 Véase W. EIJIK, «Los criterios de la individualidad orgánica y el estatuto bioantropológico del embrión preimplantatorio», en El embrión bumano en la fase de preimplantación. Aspectos científicos y consideraciones bioéticas, Actas de la XII Asamblea General de la PAV, 27 de febrero-1 de marzo de 2006, Madrid, 2008, pp. 85 y ss. 
tínez y Nicolás Jouve de la Barreda dicen expresamente: «La independencia corporal es un criterio de naturaleza jurídica según el cual un ser humano lo es sólo en la medida que se evidencia una independencia corporal y metabólica respecto a otro. Este criterio se soporta sobre la "teoría del portio mulieris" derivada de una valoración que supuestamente se sigue del Derecho romano. Autores como Charles Maynz, Ursicinio Álvarez y Sebastián Artiles hacen uso de él para objetar en contra de un estatuto antropológico en el embrión. Según ellos, el embrión debería ser considerado más como una parte de la mujer o "porción de su cuerpo" antes que como un individuo autónomo. Así, según este criterio, al embrión no se le podría reconocer una condición de individualidad ${ }^{33}$. Estos autores no niegan la existencia de vida al embrión, pero lo que sí dejan claro es que el embrión no reúne las condiciones necesarias todavía (porque se encuentra en una fase de vida primaria) para alcanzar esa «individualidad» que mencionan.

Cosa distinta es cuando nos encontramos que el ser que nace desprendiéndose del seno materno es un feto, ya que éste es definido [art. 3, apartado $n$ ), de la Ley 14/2007, LIB] también como un embrión pero con apariencia bumana y con sus órganos formados, que en cierta manera nos hace recordar la exigencia de la figura bumana que se contemplaba como requisito para adquirir la condición de persona tanto en el Derecho romano como en el art. 30 del Código Civil anterior a la actual reforma. Hoy no aparece en el nuevo art. 30, pero interpretamos no que no se exija, sino que el nuevo art. 30 prescinde de mencionarlo ya que se encuentra vigente en el art. 3, letra $n$ ), de la Ley 14/2007 (LIB) y, hasta el momento, no se ha producido ninguna derogación del mismo en la reciente Ley 20/2011, de 21 de julio, del Registro Civil, ni en ninguna otra norma. Por consiguiente, consideramos que el actual art. 30 del Código Civil, aunque no lo diga expresamente, cuando habla de nacimiento con vida está haciendo referencia a un feto que debe haber alcanzado apariencia bumana y con sus órganos formados, tal y como hemos visto que se contempla en el art. 3, letra $n$ ), de la Ley 14/2007.

Finalmente, estimamos que el periodo de gestación adecuado para alcanzar el nivel o fase de vida más idónea para adquirir personalidad ha

33 Luis Vivanco, Alfredo Martínez y Nicolás Jouve de La BarredA, «Valoración bioética y biojurídica del diagnóstico genético preimplantatorio en España», Cuadernos de Bioética, vol. XXI, 2." ed., 2010, p. 222. Véase, además, Luis Vivanco, Blanca Bartolomé, Montserrat SAN MARTín y Alfredo MARTíNEZ, «La utilización del término preembrión en la literatura científica», Journal of the American Society for information Science and Technology, mayo de 2011, pp. 987 y ss. 
de ser seis meses de gestación, ya que superado dicho tiempo, y a pesar de que nazcan muertos, podrán figurar en un archivo del Registro Civil, aunque sin efectos jurídicos, pero pudiendo otorgarles sus progenitores un nombre, tal y como se establece en la disposición adicional cuarta de la Ley 20/2011, de 21 de julio, del Registro Civil, al decir:

«Figurarán en un archivo del Registro Civil, sin efectos jurídicos, los fallecimientos que se produzcan con posterioridad a los seis meses de gestación y no cumplieran las condiciones previstas en el art. 30 del Código Civil, pudiendo los progenitores otorgar un nombre.

Este archivo quedará sometido al régimen de publicidad restringida».

Interpretando esta disposición, hay quien duda que la fórmula legal empleada («sin efectos jurídicos») en dicho texto sea del todo eficaz. La razón principal que se ha apuntado para admitirla es de carácter sociológico, al considerarse digno de respeto el sentimiento y sensibilidad de unos padres que han visto nacer muerto un feto con más de seis meses de gestación ${ }^{34}$. Por nuestra parte consideramos que el legislador ha tenido la intención de destacar la importancia de aquellos fetos de más de seis meses de gestación que encontrándose ya formados, de conformidad con la definición de feto que expresa la LIB, si hubieran nacido vivos no se hubiera dudado de la adquisición de su personalidad aunque instantes después hubiesen fallecido.

Ahora bien, los fetos que nazcan vivos y desprendidos del seno materno con menos de seis meses la Ley del Registro Civil no los menciona en ningún sentido, por lo que presumimos deben ser considerados personas, ya que cumplen los requisitos exigidos por el art. 30 del Código Civil, esto es, nacer vivo y desprendido enteramente del seno materno. De todas formas, donde sí están contemplados es en el art. 28.3 de la Ley 14/2007 (LIB) al establecer:

«Los fetos expulsados prematura y espontáneamente serán tratados clínicamente mientras mantengan su viabilidad biológica, con el único fin de favorecer su desarrollo y autonomía vital».

${ }^{34}$ María Asunción LinaCero de la Fuente, «La nueva redacción del art. 30 del Código Civil y la creación de un archivo especial para hacer constar los fallecimientos con posterioridad a los seis meses de gestación en la Ley 20/2011, de 21 de julio, del Registro Civil», op. cit., p. 1359. 
Como se puede apreciar, de nuevo nos encontramos con la necesidad de distinguir entre la vida biológica de la persona y la vida legal necesaria para adquirir la personalidad jurídica. De ahí que el legislador en dicho artículo hable de fetos expulsados, no de fetos nacidos, pero que tienen vida biológica. Por otro lado, al ser prematuros nos están indicando que son embriones que, si bien tienen apariencia humana y formados sus órganos [según el art. 3.n) LIB], sin embargo, no han alcanzado un periodo de gestación apropiado (seis meses). Con todo, estos fetos, a tenor del actual art. 30 del Código Civil, cumplen con los requisitos para adquirir personalidad jurídica, al no exigirse en el mismo un periodo mínimo de gestación, pudiendo nacer con vida y apreciándose que estaríamos ante un feto, es decir, embrión con apariencia humana y con sus órganos formados, descartando cualquier ser monstruoso o con apariencia no humana, recordándonos — una vez más - los tradicionales requisitos del nacimiento en el Derecho romano.

\section{CONCLUSIONES}

Con este trabajo hemos pretendido demostrar que, a pesar de la reforma que se ha producido en el art. 30 del Código Civil, los requisitos para la adquisición de la personalidad que estuvieron vigentes en el mundo romano han tenido su supervivencia en el tiempo. Es verdad que, en el nuevo artículo mencionado, no se trata de forma expresa de la «figura humana» como condicionante para que el ser que se desprende del seno materno se le considere persona, pero si se conecta dicho texto con otros de la legislación biomédica puede llegarse a la conclusión que los preceptos del Derecho romano siguen estando presentes.

Como hiciera el jurista romano apoyándose en la ciencia de su época, el jurista del siglo XXI hace lo mismo. Y en ese apoyo descubre que no puede desterrar de su ámbito de aplicación conceptos como «feto»o «apariencia humana», porque, aunque no los incluya en la nueva redacción del art. 30 del Código Civil, tiene el deber de contemplarlos y respetarlos a tenor de la legislación biomédica que dicta las definiciones de aquellos conceptos que se fundamentan en conocimientos científicos, técnicos y jurídicos, tal como lo expresa el apartado IV del Preámbulo de la Ley 14/2007, de investigación biomédica.

Por todo lo expuesto, y en contra de opiniones de civilistas recientes, consideramos que el requisito de la «figura humana» hay que seguir 
aceptándolo para la adquisición de la personalidad, a pesar de que no se mencione expresamente en el actual art. 30 del Código Civil. Su referencia en la legislación biomédica mencionada, así como la ambigüedad del art. 30 al hablar simplemente de «nacimiento con vida», nos reafirma en la idea de que lo exigido en la legislación romana sobre esta materia está más vivo que nunca. 